\title{
CONSTRAINT CORRECTION OF FRACTURE TOUGHNESS CTOD FOR FRACTURE PERFORMANCE EVALUATION OF STRUCTURAL COMPONENTS
}

\author{
F. Minami ${ }^{1}$, T. Inoue ${ }^{2}$ and K. Arimochi ${ }^{3}$ \\ ${ }^{1}$ Dept. Manufacturing Science, Osaka University, 2-1, Yamada-Oka, Suita, Osaka, JAPAN \\ ${ }^{2}$ Nippon Steel Corporation, 20-1 Shintomi, Futtsu, Chiba, JAPAN \\ ${ }^{3}$ Sumitomo Metal Industries, LTD., 1-8, Fuso-Cho, Amagasaki, Hyogo, JAPAN
}

\begin{abstract}
Corrections of CTOD for constraint loss in large-scale yielding conditions are made on the basis of the Weibull stress fracture criterion. A CTOD ratio $\beta=\delta_{3 P} / \delta_{W P}$ was introduced, where $\delta_{W P}$ is the CTOD of a wide plate component and $\delta_{3 P}$ is an equivalent CTOD of the fracture toughness specimen at which the toughness specimen gives a compatible Weibull stress with the wide plate. CTOD toughness scaling diagrams with $\beta$ are constructed, including effects of the work hardening property of materials, crack size in the component and the Weibull modulus $m$. The CTOD ratio $\beta$ is decreased to a large extent after full yielding, which is more significant for a high yield ratio and short/deep crack. Case studies are presented on the fracture transferability assessment of high strength structural steels with different work hardening properties.
\end{abstract}

\section{KEYWORDS}

brittle fracture, constraint effect, transferability, CTOD toughness, fracture performance, Weibull stress

\section{INTRODUCTION}

The fracture mechanics approach to structural design and material selection relies on the stress intensity factor $K$, crack tip opening displacement (CTOD, $\delta$ ) and $J$ integral as the controlling parameters for stress fields ahead of a crack. In large-scale yielding conditions, however, the actual stress fields deviate from the $K$ - and $J$ controlled fields and depend significantly on the crack size and geometry of specimens employed. This is due to the constraint effect on the crack-tip plasticity. A loss of constraint resulting from large-scale yielding relaxes the stress elevation for notched-tension panels and shallow-notch specimens, while deep-notch bend and compact specimens maintain a high level of crack tip constraint. Such constraint loss leads to an apparently increased fracture resistance $K_{c}, \delta_{c}$ and $J_{c}$ for the former configurations. In order to characterize the constraint effect on the crack tip condition, the constraint parameters, $T$-stress and $Q$-parameter were implemented in the $K$ - and $J$-controlled stress fields, respectively [1-4]. Nevertheless, these two-parameter characterizations posed an essential problem in the fracture assessment; the $T$-stress and $Q$-parameter at fracture are not material constants but depend on the geometry of specimens. On the other hand, Anderson \& Dodds [5, 6] have proposed a toughness scaling model (TSM) to correct the fracture toughness for constraint loss in large-scale yielding conditions. This model insists a similarity between near-tip stress contours in different yielding conditions, and 
transfer the fracture toughness in large-scale yielding to one under small-scale yielding with equivalent stressed areas ahead of a crack. For simplicity, the TSM does not reflect the variation of stresses within near-tip stress contours and not consider a statistical aspect of cleavage fracture. In order to overcome limitations of the TSM, a modified toughness scaling with the Weibull stress was developed [7, 8], which requires the attainment of a specified Weibull stress to cause cleavage fracture at the same probability in different specimen geometry. These methodologies focus the attention on toughness scaling in small-scale yielding conditions. From a structural design point of view, however, the fracture toughness to be used for the fracture performance evaluation in service conditions should be quantified in conjunction with the constraint state. This paper addresses the constraint correction of CTOD, based on the Weibull stress criterion, as a function of the deformation level of structural components. A parametric study is performed on the CTOD correction factors, including the work hardening property of materials, crack size in components and the Weibull modulus $m$ related to a scatter in the material fracture toughness.

\section{CTOD TOUGHNESS SCALING WITH THE WEIBULL STRESS}

This paper constructs CTOD toughness scaling diagrams to correct a constraint loss in large-scale yielding conditions. The Weibull stress $\sigma_{W}$ is used as a driving force for cleavage fracture. The Weibull stress $\sigma_{W}$ is derived from a statistical characterization of instability of microcracks in the Local Approach [9, 10], and given by the integration of a near-tip stress $\sigma_{e f f}$ over the fracture process zone $V_{f}$ in the form

$$
\sigma_{W}=\left[\frac{1}{V_{0}} \int_{V_{f}}\left[\sigma_{e f f}\right]^{m} d V_{f}\right]^{1 / m}
$$

where $V_{0}$ and $m$ are a reference volume and a material parameter, respectively. The critical Weibull stress $\sigma_{W, c r}$ obeys the Weibull distribution with two parameters $m$ and $\sigma_{u}$

$$
F\left(\sigma_{W, c r}\right)=1-\exp \left[-\left(\frac{\sigma_{W, c r}}{\sigma_{u}}\right)^{m}\right]
$$

which is considered as a material property independent of the specimen geometry. This enables the fracture strength/toughness scaling among different specimen configurations. Figure 1 illustrates the process of CTOD scaling between the fracture toughness specimen with a high constraint level and a wide plate component. This paper defines the CTOD ratio $\beta[11]$ as

$$
\beta=\delta_{3 P} / \delta_{W P}
$$
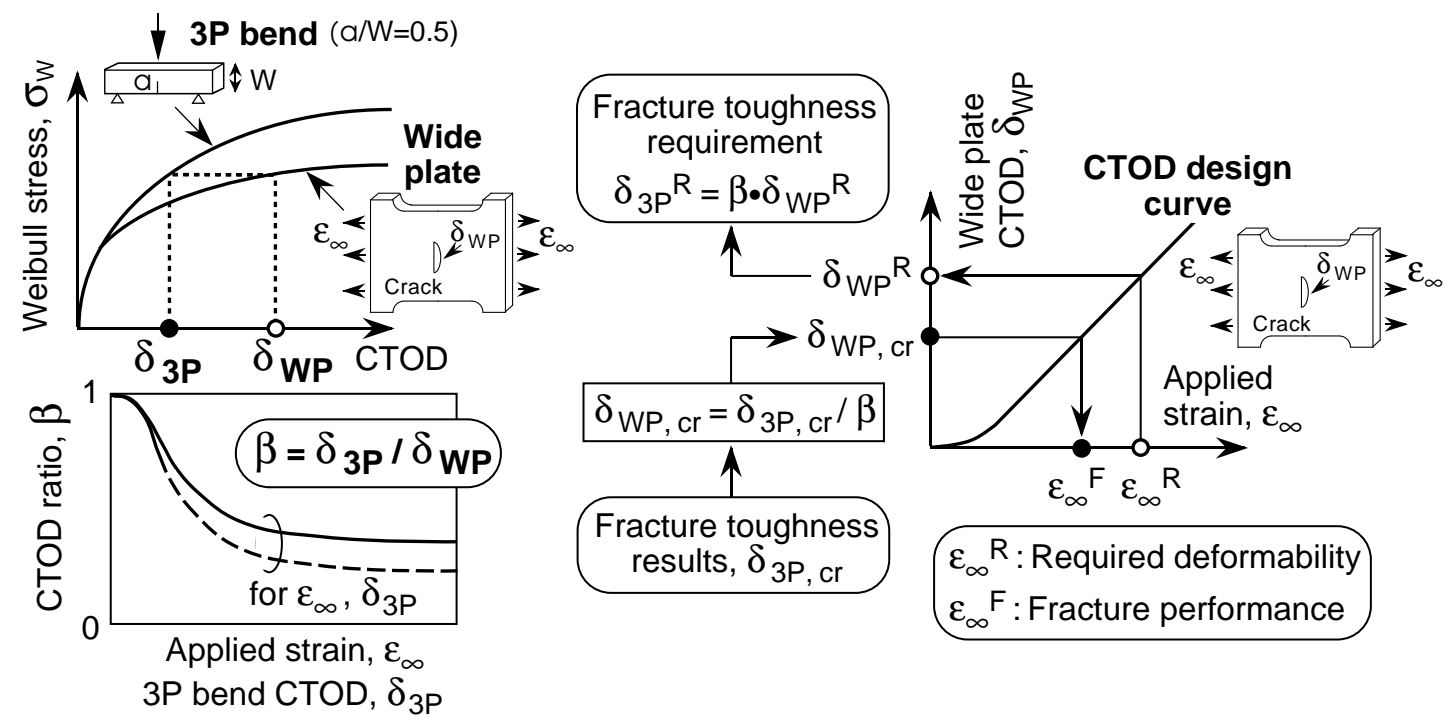

Figure 1 : CTOD toughness scaling between wide plate component and fracture toughness specimen. 
where $\delta_{W P}$ is a wide plate CTOD, and $\delta_{3 P}$ is an equivalent CTOD at which the fracture toughness specimen gives a compatible Weibull stress with the wide plate. The establishment of $\beta$ as a function of (a) applied strain $\varepsilon_{\infty}$ of wide plate and (b) CTOD $\delta_{3 P}$ of toughness specimen enables the fracture control assessments with the CTOD design curve (relationship between $\varepsilon_{\infty}$ and $\delta_{W P}$ ) conventionally used in the structural engineering field: - Determination of required fracture toughness $\delta_{3 P}{ }^{R}$ to meet a design solution $\varepsilon_{\infty}{ }^{R}$ of structural components. - Estimation of fracture performance $\varepsilon_{\infty}{ }^{F}$ of structural components from fracture toughness test results $\delta_{3 P, c r}$. In this paper, an effective stress [12] considering a random spacial distribution of microcracks was employed as the near-tip stress $\sigma_{e f f}$ in Eqn. 1. The selection of $V_{0}$ does not affect the transferability analysis of fracture mechanics test results, although the absolute value of the Weibull stress depends on $V_{0}$. Furthermore, the Weibull modulus $m$ has no connection with $V_{0}$. Hence, a unit volume was adopted as $V_{0}$ for convenience [12].

\section{TRANSFERABILITY ANALYSIS OF FRACTURE MECHANICS TEST RESULTS}

Firstly, advantages of the Weibull stress based approach to cleavage fracture are demonstrated for two structural steels with different work hardening properties. Materials used were high strength steels of 490 and $950 \mathrm{MPa}$ class, HT490 and HT950, with a plate thickness of $25 \mathrm{~mm}$. Table 1 shows the chemical composition and mechanical properties of these steels. Low and extremely high $Y R$ (yield-to-tensile ratio) values are noted for HT490 and HT950 steels, respectively. Figure 2 shows the configuration of test specimens used. Fracture toughness tests were conducted with compact and 3-point bend specimens. The compact and deep-notch bend specimens with $a / W=0.5$ ( $a$ : notch length, $W$ : specimen width) were of a standard type specified in the test standard, BS 7448 Part 1: 1991. A shallow notch of $a / W=0.1$ was also prepared for the bend specimen. The tension specimen included a double-edge notch of $2 a / 2 W=0.3$, where the specimen width $2 W=100 \mathrm{~mm}$. The notch tip of each specimen was finished with a fatigue precrack of length $2.0 \sim 2.5 \mathrm{~mm}$. Tests were conducted at $-100{ }^{\circ} \mathrm{C}$ for both steels.

Test results were given in Fig. 3 in terms of cumulative distributions of the critical CTOD at brittle fracture initiation. The CTOD values were calculated according to BS7448 for the compact and deep-notch bend

TABLE 1 : CHEMICAL COMPOSITION AND MECHANICAL PROPERTIES OF STRUCTURAL STEELS USED.

\begin{tabular}{|c|c|c|c|c|c|c|c|c|c|c|c|}
\hline & \multicolumn{10}{|c|}{ Chemical composition (mass \%) } \\
\cline { 2 - 11 } & $\mathrm{C}$ & $\mathrm{Si}$ & $\mathrm{Mn}$ & $\mathrm{P}$ & $\mathrm{S}$ & $\mathrm{Ni}$ & $\mathrm{Cr}$ & $\mathrm{Mo}$ & $\mathrm{Cu}$ & $\mathrm{V}$ & Ceq \\
\hline HT490 & 0.17 & 0.33 & 1.22 & 0.012 & 0.004 & 0.02 & 0.03 & 0.01 & - & - & 0.40 \\
\hline HT950 & 0.12 & 0.19 & 0.89 & 0.004 & $<0.001$ & 2.61 & 0.58 & 0.55 & 0.30 & 0.05 & 0.60 \\
\hline
\end{tabular}

\begin{tabular}{|c|c|c|c|c|}
\hline \multirow{2}{*}{} & \multicolumn{4}{|c|}{ Mechanical properties (Rolling direction) } \\
\cline { 2 - 5 } & $\sigma_{\mathrm{Y}}(\mathrm{MPa})$ & $\sigma_{\mathrm{T}}(\mathrm{MPa})$ & $\mathrm{YR}=\sigma_{\mathrm{Y}} / \sigma_{\mathrm{T}}$ & $\varepsilon_{\mathrm{T}}(\%)$ \\
\hline HT490 & 356 & 520 & 68.3 & 13.8 \\
\hline HT950 & 1026 & 1036 & 99.1 & 6.2 \\
\hline
\end{tabular}

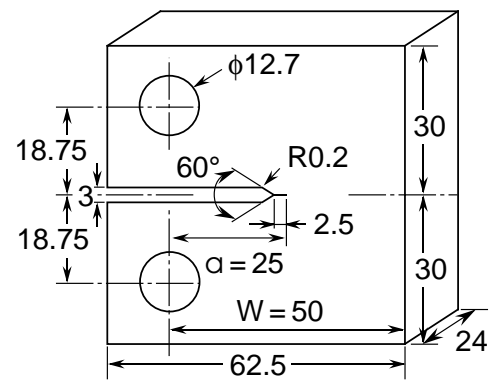

$\sigma_{\mathrm{Y}}$ : Yield stress, $\sigma_{\mathrm{T}}$ : Tensile strength, $\varepsilon_{\mathrm{T}}$ : Uniform elongation

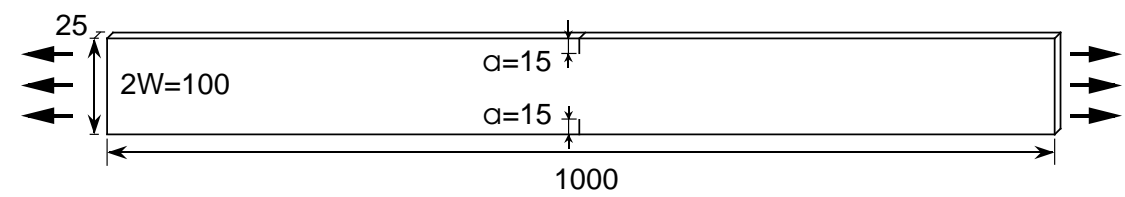

(a-2) Double-edge notched tension specimen for HT490

(a-1) Compact specimen for HT490
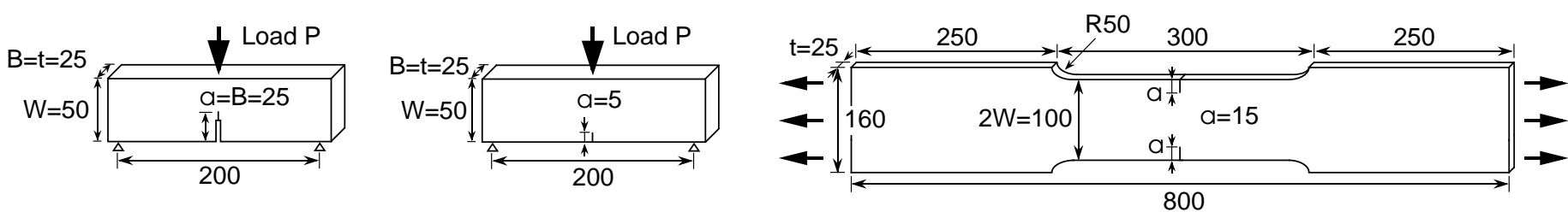

(b-1) 3-point bend specimens for HT950

(b-2) Double-edge notched tension specimen for HT950

Figure 2 : Fracture mechanics specimens used in experiments. 


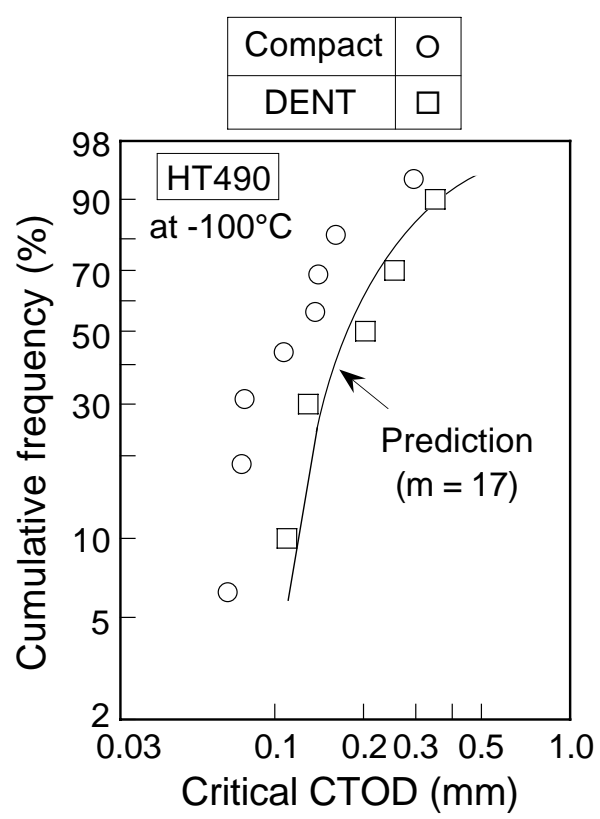

(a) HT490 steel

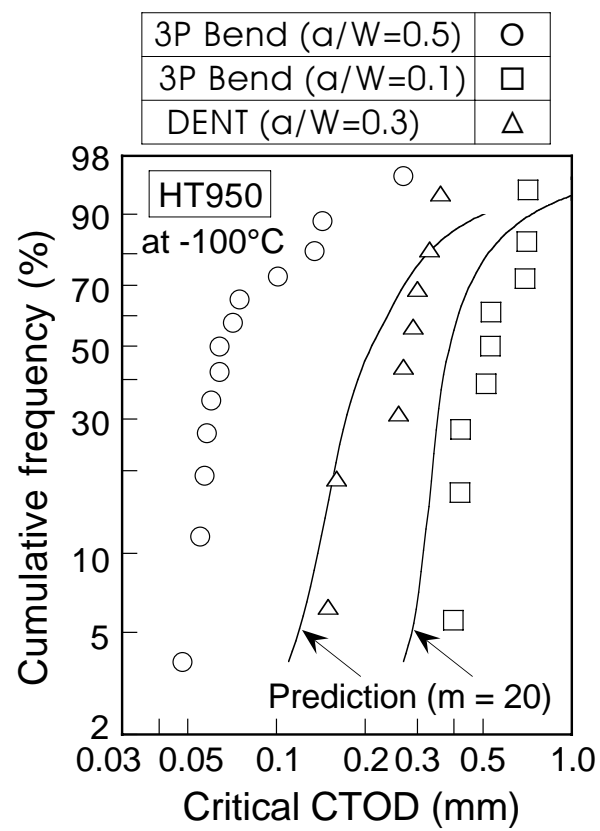

(b) HT950 steel

Figure 3 : CTOD test results and estimation of critical CTOD of tension and shallow-notch bend specimens.

specimens and by the Dugdale model for the tension specimen. One for the shallow-notch bend was evaluated by a method proposed by Wang \& Gordon [13], which is based on the area under the load versus CMOD record (CMOD: crack mouth opening displacement). A marked effect of constraint loss is observed in the tension and shallow-notch bend test results; larger critical CTOD than the standard fracture toughness specimen.

Using the CTOD results of the compact and deep-notch bend specimens, the critical CTOD values for the tension and shallow-notch bend specimens were estimated on the basis of the Weibull stress criterion; independence of $\sigma_{W, c r}$ on the specimen geometry. An iteration procedure [12] was employed for the determination of the $m$-value. The Weibull parameters $m$ determined were 17 and 20 for HT490 and HT950 steels, respectively. The estimated results are drawn with a solid line in Fig. 3. A good agreement is found between the estimation and experimental data. One may argue the reliability of the $m$-value determined by the iteration procedure; non-uniqueness in small-scale yielding conditions [14]. In order to address this discussion point, a bias was introduced in the range $0.5 \widehat{m} \leq m \leq 1.5 \hat{m}$, where $\widehat{m}$ is the Weibull modulus determined by the iteration method ( $\widehat{m}=17,20$ in this case). The numerical study with $m=\widehat{m} \pm 0.5 \widehat{m}$ indicated that such bias hardly affected the estimation of the critical CTOD. Studies on the fracture transferability assessment of welded joints are published in the recent paper [11].

\section{CTOD TOUGHNESS SCALING DIAGRAM}

For applications of the Weibull stress approach to structural design and material selection, a framework begins in this paper to construct CTOD toughness scaling diagrams. A tension wide plate with a surface crack and a standard 3-point bend specimen of $a / W=0.5$ were considered (Fig. 4). A parametric study was conducted on controlling factors of the CTOD ratio $\beta$. Table 2 gives basic variables used in the FE-analysis (3D FEM), which include the work hardening property, crack size in the wide plate and the Weibull modulus $m$;

- Work hardening property: The yield ratio $Y R\left(=\sigma_{Y} / \sigma_{T}\right)$ was varied in the range 0.60 to 0.95 with a given yield stress $\sigma_{Y}=583 \mathrm{MPa}$ and tensile strength $\sigma_{T}=711 \mathrm{MPa}$. These $\sigma_{Y}$ and $\sigma_{T}$ values were referred to the mechanical properties of a high strength pipeline steel [15].

- Crack size; The crack length $2 a$ and depth $b$ analyzed were in the range $16 \leq a \leq 100 \mathrm{~mm}$ and $1 \leq b \leq 6 \mathrm{~mm}$. - Weibull modulus $m$; The $m$-value ranged from 15 to 40 , where $m=20$ was used as a standard value.

The yield ratio $Y R$ exerted a large influence on the CTOD ratio $\beta$. Figure 5 shows the effect of $Y R$ on the CTOD ratio $\beta$ for a surface crack of $2 a=40 \mathrm{~mm}$ and $b=6 \mathrm{~mm}$, where the results are given as a function of the non- 
TABLE 2 : BASIC VARIABLES EMPLOYED IN PARAMETRIC STUDY OF CTOD RATIO $\beta$.

\begin{tabular}{|c|c|c|c|c|c|c|c|c|}
\hline & \multicolumn{4}{|c|}{ Mechanical properties } & \multicolumn{3}{|c|}{ Crack size } \\
\hline & & $\begin{array}{c}\sigma_{Y} \\
(\mathrm{MPa})\end{array}$ & $\begin{array}{c}\sigma_{\mathrm{T}} \\
(\mathrm{MPa})\end{array}$ & $\begin{array}{c}\mathrm{YR} \\
=\sigma_{\mathrm{Y}} / \sigma_{\mathrm{T}} \\
(\%)\end{array}$ & $\begin{array}{c}\varepsilon_{\mathrm{T}} \\
(\%)\end{array}$ & $\begin{array}{c}2 \mathrm{a} \\
(\mathrm{mm})\end{array}$ & $\begin{array}{c}\mathrm{b} \\
(\mathrm{mm})\end{array}$ & $2 \overline{\mathrm{a}}(\mathrm{mm})$ \\
\hline \multirow{2}{*}{$\begin{array}{c}\text { Effect of } \\
\text { YR }\end{array}$} & $\sigma_{\mathrm{T}}:$ const. & $427 \sim 675$ & 711 & $60 \sim 95$ & 11.4 & 40 & 6 & 13.8 \\
\hline & $\sigma_{Y}:$ const. & 583 & $614 \sim 972$ & $60 \sim 95$ & 11.4 & 40 & 6 & 13.8 \\
\hline \multirow{7}{*}{$\begin{array}{c}\text { Effect of } \\
\text { crack size }\end{array}$} & \multirow{4}{*}{$\begin{array}{l}\text { Crack } \\
\text { length } \\
\text { effect }\end{array}$} & \multirow{7}{*}{583} & \multirow{7}{*}{711} & \multirow{7}{*}{82} & \multirow{7}{*}{11.4} & 100 & \multirow{4}{*}{6} & 18.2 \\
\hline & & & & & & 40 & & 13.8 \\
\hline & & & & & & 30 & & 12.0 \\
\hline & & & & & & 16 & & 7.4 \\
\hline & \multirow{3}{*}{$\begin{array}{l}\text { Crack } \\
\text { depth } \\
\text { effect }\end{array}$} & & & & & \multirow{3}{*}{40} & 1 & 2.5 \\
\hline & & & & & & & 3 & 7.4 \\
\hline & & & & & & & 6 & 13.8 \\
\hline
\end{tabular}

2व: Equivalent through-thickness crack size
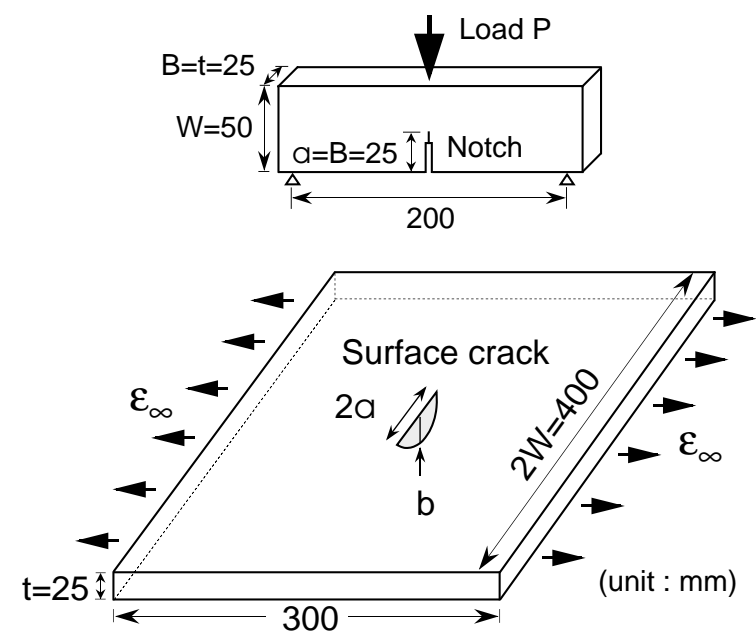

Figure 4: Wide plate and 3-point bend specimen used for parametric study of $\beta$.
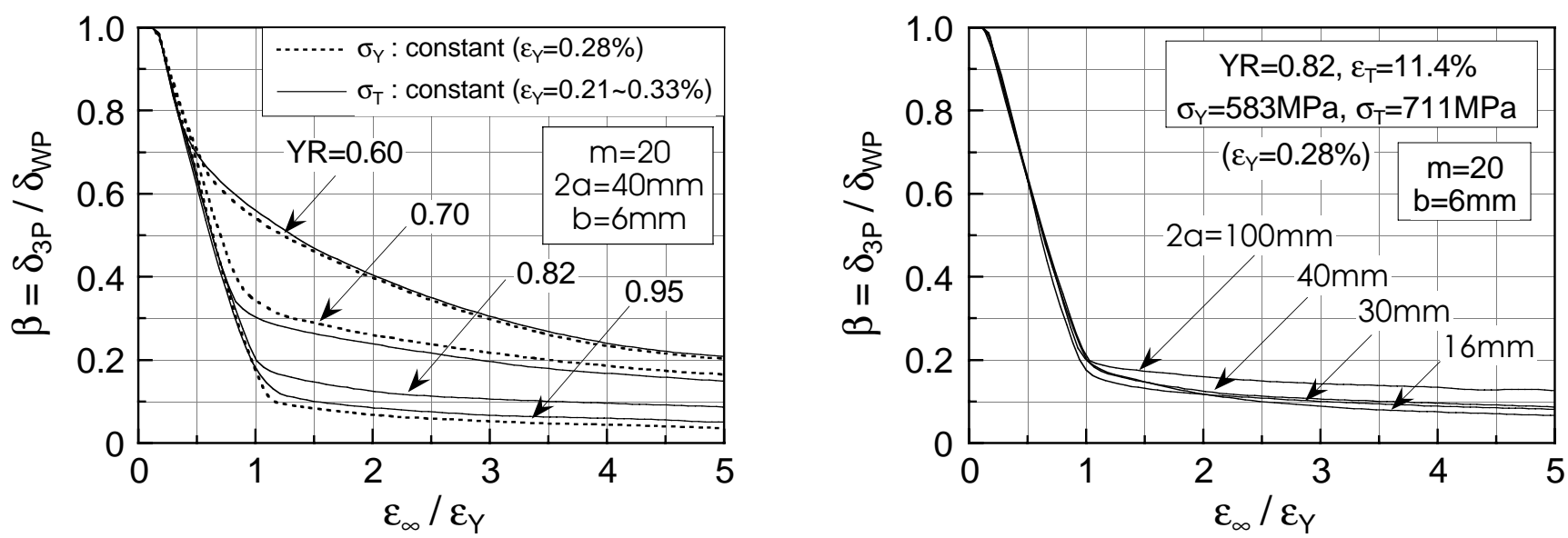

Figure 5 : Effect of yield ratio $Y R$ on CTOD ratio $\beta$. Figure 6 : Effect of crack length $2 a$ on CTOD ratio $\beta$.

dimensional overall strain $\varepsilon_{\infty} / \varepsilon_{Y}$ of the wide plate. The CTOD ratio $\beta$ decreases to a large extent after full yielding of the wide plate, which is more significant for a high $Y R$. This is mainly related to the crack opening behavior of the wide plate. Low work hardening $(=$ high $Y R)$ yields a strain localization in the crack tip region, which produces a large CTOD $\delta_{W P}$ resulting in a low $\beta$. The change in $Y R$ under a constant $\sigma_{Y}$ reached substantially the same results as under a constant $\sigma_{T}$. Similar effects were observed for another crack size.

Figure 6 shows the effect of crack length in the wide plate. The CTOD ratio $\beta$ seems to be not so sensitive to the crack length. This is due to the following aspects: Longer crack provides a larger CTOD. At the same time, the fracture process zone $V_{f}$ is enlarged with the crack front length, leading to amplification of the Weibull stress $\sigma_{W}$. Namely, the crack length $2 a$ brings about two opposite influences on the CTOD ratio $\beta$. The positive and negative effects are almost evenly balanced, so that the CTOD ratio $\beta$ seems to be insensitive to the crack length $2 a$ in the range of calculations in this paper. The crack depth effect on the CTOD ratio $\beta$ is presented in Fig. 7. A deep crack gives a low $\beta$, although the near-tip stress fields are activated in the deep crack. Low $\beta$ for the deep crack was induced by a dominant action of crack opening; deep crack produces a large CTOD. However, the crack depth effect is weakened in a large-scale yielding range.

The influence of the Weibull modulus $m$ is presented in Fig. 8. The CTOD ratio $\beta$ was rather insensitive to the $m$-value. The exception was found in the results for a long crack of $2 a=100 \mathrm{~mm}$. The Weibull stress $\sigma_{W}$ consists of a stress term and a volume term. The stress term is given by $\left(\sigma_{e f f}^{m}\right)^{1 / m}$ and almost independent of $m$. On the other hand, the volume term includes the shape parameter $m$ in the form $V_{f}^{1 / m}$. The latter term becomes active, when a large process zone $V_{f}$ is combined with a small $m$. Such volume effect elevated $\beta$ slightly. Further work is in progress to establish the CTOD toughness scaling diagram. 


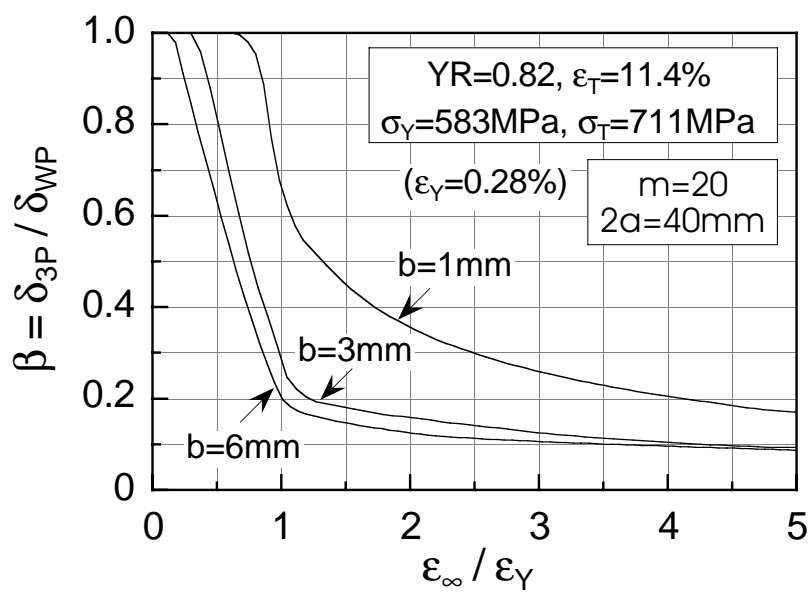

Figure 7 : Effect of crack depth $b$ on CTOD ratio $\beta$.

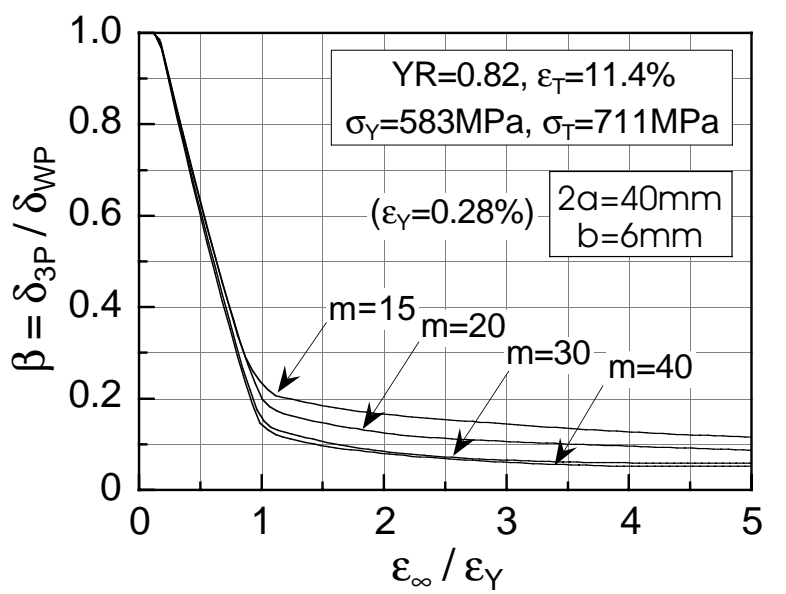

Figure 8 : Effect of Weibull modulus $m$ on CTOD ratio $\beta$.

\section{CONCLUSIONS}

This paper presented the CTOD toughness scaling between structural components and fracture toughness specimens. Diagrams to correct the CTOD for constraint loss in large-scale yielding were constructed as a function of the deformation level of components, based on the Weibull stress fracture criterion. A CTOD ratio $\beta=\delta_{3 P} / \delta_{W P}$ was introduced, where $\delta_{W P}$ is the CTOD of a wide plate component and $\delta_{3 P}$ is an equivalent CTOD of the fracture toughness specimen at which the toughness specimen gives a compatible Weibull stress with the wide plate. Major factors controlling $\beta$ were the work hardening property of materials and crack size in the component. A low $\beta$ was related to a low work hardening ( $=$ high yield ratio) and a deep crack in the component. The CTOD toughness scaling diagrams enable a reasonable fracture assessment to eliminate an excessive conservatism in structural design and material toughness requirement.

\section{REFERENCES}

[1] Betegón, C. and Hancock, J. W. (1991). Journal of Applied Mechanics, 58, pp. 104-110.

[2] Wang, Y.-Y. (1991). Ph. D. Thesis, Massachusetts Institute of Technology, USA.

[3] O'Dowd, N. P. and Shih, C. F. (1991). Journal of Mechanics and Physics of Solids, 39, pp. 989-1015.

[4] O'Dowd, N. P. and Shih, C. F. (1992). Journal of Mechanics and Physics of Solids, 40, pp. 939-963.

[5] Anderson, T. L. and Dodds, Jr. R. H. (1991). Journal of Testing and Evaluation, 19, pp. 123-134.

[6] Dodds, Jr. R. H., Anderson, T. L. and Kirk, M. T. (1991). International Journal of Fracture, 48, pp. 1-22.

[7] Gao, X., Ruggieri, C. and Dodds, Jr. R. H. (1998). International Journal of Fracture, 92, pp. 175-200.

[8] Miyata, T., Tagawa, T. and Hongkai, Y. (2000). Journal of Testing and Evaluation, 28, pp. 62-65.

[9] Beremin, F. M. (1983). Metallurgical Transactions A, 14A, pp. 2277-2287.

[10] Mudry, F. (1987). Nuclear Engineering Design, 105, pp. 65-76.

[11] Minami, F., Katou, T., Nakamura, T. and Arimochi, K. (1999). Proc. 18th Int. Conf. on Offshore Mechanics and Arctic Engineering, ASME, St. Johns, Newfoundland, OMAE99/MAT-2130.

[12] Minami, F., Brückner-Foit, A., Munz, D. and Trolldenier, B. (1992). International Journal of Fracture, 54, pp. 197-210.

[13] Wang, Y.-Y. and Gordon, J. R. (1992). Proc. Int. Conf. on Shallow Crack Fracture Mechanics, Toughness Tests and Applications, TWI, Abington, Cambridge, Paper 28.

[14] Gao, X., Ruggieri, C. and Dodds, Jr. R. H. (1998). International Journal of Fracture, 92, pp. 175-200.

[15] Minami, F., Ohata, M., Toyoda, M., Tanaka, T., Arimochi, K., Glover, A. G. and North, T. H. (1995).

Pipeline Technology, 1, pp. 441-461. 